\title{
EAl Endorsed Transactions

\section{Westminster Serious Games Platform (wmin-SGP) a tool for real-time authoring of roleplay simulations for learning}

\author{
D. Economou ${ }^{1, *}$, I. Doumanis ${ }^{2}$, F. Pedersen ${ }^{3}$, P. Kathrani ${ }^{4}$, M. Mentzelopoulos ${ }^{1}$, V. Bouki ${ }^{1}$, \\ N. Georgalas ${ }^{4}$
}

${ }^{1}$ Department of Computer Science, Faculty of Science and Technology, University of Westminster, 115 New Cavendish Street, W1W 6UW, London, UK

${ }^{2}$ CTVC Ltd, McBeath House, 310 Goswell Road, EC1V 7LW, London, UK

${ }^{3}$ Department of Politics and International Relations, Faculty of Science and Technology, University of Westminster, 32/38

Wells Street, W1T 3UW, London, UK

${ }^{3}$ Westminster Law School, University of Westminster, 4-12 Little Titchfield Street, W1W 7BY115,London, UK

${ }^{4}$ BT Intel Co-lab, British Telecom, Ipswich, UK

\section{Abstract}

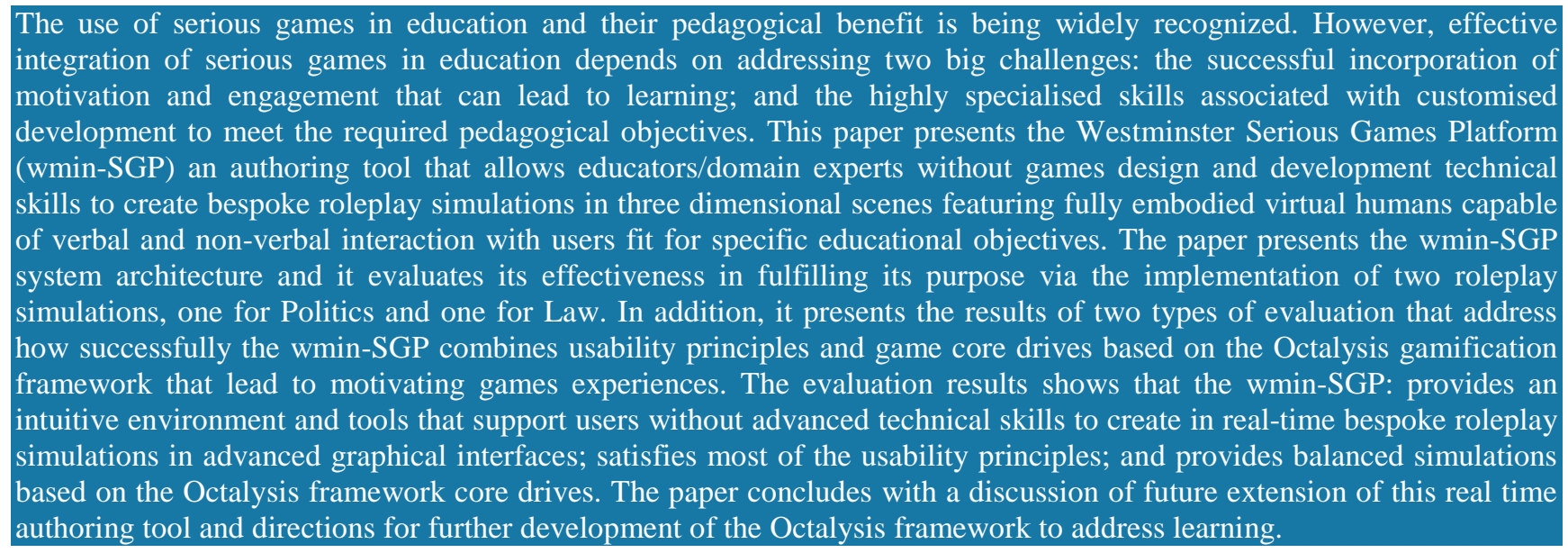

Keywords: Gamification, virtual reality, Octalysis framework, roleplay simulations, embodied virtual humans, learning.

Received on 15 November 2015, accepted on 24 January 2016, published on 27 June 2016

Copyright (C) 2016 D. Economou et al., licensed to EAI. This is an open access article distributed under the terms of the Creative Commons Attribution licence (http://creativecommons.org/licenses/by/3.0/), which permits unlimited use, distribution and reproduction in any medium so long as the original work is properly cited.

doi: 10.4108/eai.27-6-2016.151524

*D.Economou. Email:D.Economou@westminster.ac.uk 


\section{Introduction}

Research in recent years has highlighted the educational values of "games", "game simulations" and "serious games". Computer games have now been around for over three decades and they have been employed as pedagogic tools for drill and practice, warm-up activities and rewards. The term games-based learning (GBL) has been attributed to the use of computer games that are thought to have educational value, however there has been much debate surrounding this theory [42]. Simulations have also been recognized as "a very effective and stimulating didactic tool" [45] and they are being increasingly adopted as a pedagogical tool by schools and industry all over the world [1]. This is due to the fact that by linking the learning environment with the actual environment they are more likely to capture the imagination of students than traditional forms of classroom teaching [53] and they fulfil objectives of promoting integrative learning and enhancing team development [58].

The terms games, game simulations and serious games have been used interchangeably. However, it is worth elucidating the recognition of:

- games as recreational activities whose main objective is entertainment;

- serious games as aiming at having other purpose besides entertainment, such as education or training;

- $\quad$ simulations as trying to recreate a situation that occurs in real life through a game.

Roleplay simulations [19], where learners take on the role profiles of specific characters or organisations in a contrived setting are currently used at the School of Law and the Department of Politics and International Relations at the University of Westminster in a very effective way. The domain experts have great experience in creating game simulations suitable to the learning objectives of the subject they teach and the learning abilities of their students. However, the domain experts do not have the required specialized technical skills to build digital roleplay simulations that we classify as serious games. In addition, those modules are not taught in lecture theatres equipped with computers that could be used to run digital roleplay game simulations. The University of Westminster supports blended learning [32] and in order to facilitate innovative teaching and learning methods and techniques that make use of digital media it provides iPads to all the undergraduate students. Thus, to maximize reach any provided educational resources should be accessible on those devices. To assist this practice emphasizing on "deep" as opposed to "surface" [14] learning, the Serious Games at Westminster (SG@W) research group developed the Westminster Serious Games Platform (wmin-SGP). The wmin-SGP consists of:

- a real-time authoring tool that allows the creation of bespoke roleplay simulations without the need of specialist technical skills;

- a play mode which engages students in rich experiential learning using a three dimensional (3D) virtual environment (VE) enhanced with game features and Virtual Humans (VHs) - virtual embodiments supporting human-to-human or humanto-agent interaction with users by means of verbal and non-verbal discourse;

- $\quad$ the resources can be accessed on multiple platforms and devices (this feature is not currently implemented).

A number of projects have investigated the use of serious games in class with encouraging results. Enriching such games with VHs capable of engaging the learner in social activities provides the potential for rich learning experiences, as the gameplay is multimodal and learning becomes experiential. In addition, interaction in 3D VEs has been shown to increase students' attention levels by $92 \%$ and increase test scores by 35\% [58] - while at the same time creating a new level of engagement for students and teachers. However, the high cost and the complexity both in creating bespoke 3D game content and interaction with VHs (bespoke dialogues and verbal and non-verbal behaviours) to match the requirements of the game's premise deterred the wider adoption of gamebased learning featuring VHs.

This paper presents wmin-SGP and studies the pedagogical value of this real-time authoring tool in supporting the creation of motivating and engaging roleplay game simulations for learning. Section 2 of the paper provides the context to this research by presenting a background review. Section 3, presents the architecture of wmin-SGP, which includes a number of game design elements that can be used in the optimization of the experience of the player's/students journey. Section 4, presents a list of use cases that have been implemented to study the pedagogical value of wmin-SGP. Section 5, describes an expert-user evaluation of wmin-SGP using a cognitive walkthrough of the system reviewing core usability principles of the provided tools (authoring and play). Section 6, demonstrates the wmin-SGP evaluation results using the Octalysis gamification framework. The paper concludes with directions for further extension of the wmin-SGP to address the Octalysis framework evaluation results by enhancing its gamification, as well as directions for further extension of the Octalysis gamification framework itself.

\section{Background and related work}

This section provides the background to this project that combines roleplay simulations, serious games and advanced VR and fully embodied VHs.

\subsection{Simulations}

A large number of publications have in recent years highlighted the valuable contribution simulations can make to teaching [23] [54][53]. Simpson and Kaussler [53] highlighted the added value of simulations to the 
learning experience by requiring students to become more actively involved in their learning process, acquiring indepth knowledge of respective issues and then apply their problem solving and analytical skills. Kille [26] argues that students' understanding of the key concepts in their field is reinforced by actively engaging them in policy formulation and negotiation. Simulation games are frequently used in the training of civilians and military personnel [55]. They are used in situations that replicate real world situations when it is too expensive or associated with unacceptable risk to use real equipment or, as in the project proposed here, real patients.

However, simulation exercises not only enhance students' learning, they also provide them with valuable work-related skills, such as planning and negotiation skills [61]. Training scenarios can be replicated and allow for practice and critical reflection on what works and what does not. This can obviously be very valuable when attempting to assess or project the impact of new health initiatives, but also when exploring new forms of democratic engagement. This is well known among practitioners and is extensively used in emergency planning in the NHS. However, while simulations and games have been deemed appropriate (didactic) learning tools for emergency health workers and generals preparing military action [48], much less work has been done to integrate these methods into continuous learning and capacity building. It is this, and its potentially transformative effect, that Mary Flanagan explores in her Critical Play [13]. Simulations and games allow the participants to take calculated risks and to learn from both successes and failures without endangering subjects in medical trials, creating unstable democratic structures or taking costly military action.

A large number of publications have in recent years highlighted the valuable contribution that roleplay simulations can make to the teaching of international relations and environmental and health policy [36] [11][56][18]. A variety of simulations are used to raise student awareness through experiential learning of the dilemmas that persist within the area of political decisions. They help improve students' ability to critically evaluate and interpret diplomatic arguments and social arrangements, for students to understand and evaluate their world and their place in it as learners and, upon graduation, practitioners.

One domain that, traditionally, uses simulations and scenarios to support and promote learning, but made very limited use of games so far is Law [28]. Nowadays there is a demand for modernisation of legal education [52] and the use of digital roleplay simulations in this domain appears to be very suitable, as they are naturally constructed around simulations and stories. The potential of digital roleplay simulations for improving law school instruction has been acknowledged by members of the academic community [28] [41] [52] [62].

Effective game simulation scenarios that match specific learning requirements can be created by domain experts. However, domain experts in areas such as Social
Sciences, Humanities, Arts etc. are very likely to lack specialized technical skills required to build stimulating, highly interactive and appealing digital roleplay simulations.

\subsection{Games}

The main purpose of games, unlike roleplay simulations, is usually entertainment. They can seem non-educational; they are typically associated with play and childhood. Even the name implies that games are the opposite of work - and the discipline associated with it [21]. Claims that games must be used to make learning "fun” [27] ignore that students, who are deeply engaged in learning consider it both fun and hard work. Shaffer \& Gee [51] and NESTA Futurelab [35] describe how games can facilitate learning. Games encompass many attributes that enhance learning:

- $\quad$ they are immersive - they require the player to make frequent, important decisions, have clear goals, adapt to each player individually, and involve a social network [34];

- $\quad$ they are played in social environments;

- $\quad$ they require prior learning and research, as well as problem solving;

- $\quad$ they enable knowledge transferred from other spheres (life, school, other games etc);

- they are essentially experiential as they engage multiple senses.

For each action, there is a reaction. Feedback is swift. Hypotheses are tested, and users learn from the results. Immersion, a psychological sense of sensory and physical engagement resulting in one feeling "inside" an environment is another aspect of games that enhance simulation and learning. Players participate in new worlds, inhabiting roles that would otherwise be inaccessible to them; they think, act, and talk in new ways. Players can experience the ways a particular discipline thinks about and solves problems, as a physicist, a general, an astronaut, or a physician. Another critical element of games is the community that develops around them. In these communities, ideas are shared, group problem-definition and problem-solving occurs, as well as a good deal of socializing. The description of a game community mirrors closely the definition of an educational community. The community has a culture of learning; everyone is involved in a collective effort of understanding where members are valued for their contributions and helped to develop further as the group continually advances its collective knowledge and skills.

\subsection{Serious Games in education}

Serious games are becoming a recognized venue of creative attempts to develop students' skills and attributes in both formal and informal educational settings. This is due to potential benefits of their use in educational 
contexts like: massive reach; experiential learning; enquiry-based learning; self-efficacy; goal setting; cooperation; continuous feedback; enhanced brain chemistry; time on task [33]. Garris et al. [15] referred to three major factors that may have contributed to the rapid growth of serious games in professional training and educational contexts:

- the emergence of a new paradigm in the field of teaching and learning;

- the introduction of interactive technologies that actively involve students in problem solving;

- the enormous capacity of serious games to capture the students' attention and engage them in the curricular content.

Wrzesien \& Alcañiz Raya[64], conducted a thorough literature of serious games during the last decade and identified three main reasons for their growing use in education:

- they use actions rather than explanations and create personal motivation and satisfaction;

- they accommodate multiple learning styles and abilities;

- $\quad$ they foster decision-making and problem-solving activities in a virtual setting.

Thus is not surprising that serious games are being incorporated more and more into learning environments.

The incorporation of game elements in non-game contexts is widely referred to as "gamification" [4]. Gamification is being increasingly recognized as the process/technique of extracting motivating and engaging elements found in games and applying them to real-world productive or educational activities [20]. Chou [5], recognizes this process as "Human-Focused Design” or else User-Centered Design (UCD), which appreciates user motives, cognitive and emotional states and therefore optimizes for their feelings, motivations, and engagement, as opposed to "Function-Focused Design", which is designed for pure efficiency.

Some challenges in the effective use of serious games simulations in educational context are:

- the creation of bespoke game simulations to match specific educational needs;

- the incorporation of technological solutions that are appealing to students and accessible in real life educational context;

- $\quad$ the adaptation of technological solutions that are easy to use and do not require extra training by teachers;

- managing students and student activity during a teaching session;

- the successful incorporation of gamification to motivate and engage learners; like the incorporation of engaging characters that the users can interact with seamlessly and that could aid both engagement and motivation.

The following section reviews the incorporation of virtual characters in serious games.

\subsection{Virtual Humans in serious games}

Human embodiment/representation within serious games, to which we will refer to in the rest of the paper as VHs, represent the inhabitants of serious games that could feature both: human-to-human interaction or human-toagent interaction. The importance of virtual human in Serious games can be recognised if one considers the role of the human body in real life. The human body:

- provides immediate and continuous information about user presence, identity, attention [24], activity status, availability [16] and mood;

- $\quad$ sets a social distance between conversants (e.g. their actual location) [3] which helps in regulating interaction [10];

- helps in managing a smooth sequential exchange between parties by supporting speech with nonverbal communication [49].

Serious games use technology from intelligent tutoring, pedagogical agents and virtual worlds and combine those with game techniques. VHs in serious games may be equipped with a conversational and behaviour system and may have personality and emotions. They might motivate users by engage them in a discourse. In some cases, they might also perform task themselves and show how to do it. The benefits of VHs in serious games have been explored in a number of projects [12][17][31]. Rickel [46], notes that VEs with interesting VHs have a powerful ability to engage and capture our attention and leave memorable impressions.

Students, in interactive smart VEs with interested VHs, may experience the scene in a more interactive, engaging and immersive manner. Hence, the virtual experience can enhance their learning constructively by providing new educational capabilities [6]. A number of research projects have attempted to embody virtual characters with verbal and nonverbal communication and to evaluate their impact in computer-based learning environments [8][9]. The challenge is not only to make VHs look like humans, but also to make them behave as humans [7]. A key characteristic of engaging VHs is the level of intelligence and the naturalness of verbal and non-verbal interaction (e.g., gaze, facial expressions, head nods and gestures) to engage users in realistic social interactions. For example a dumb virtual human is likely to degrade the effectiveness of the experience.

The REal and Virtual Engagement in Realistic Immersive Environments (REVERIE) platform [2][44] is a gamified $\mathrm{VE}$ which brings together realistic interpersonal communication and interaction. The platform features both human-to-human and human-toagent interaction. Users can adapt the basic features of VHs, and they can create photorealistic 3D representations of themselves to interact and play games with other human-users and VHs in VEs. The REVERIE provides the tools for user-generated content (e.g., videos, images, customisable VHs, 3D objects, etc.). However, users of REVERIE have no control over the behaviours 
and dialogue content of VHs neither they can customise the VE to match different game premises. The VHs are pre-scripted by the platform's developers.

cMotion[12] is a game that uses VHs to teach emotion recognition and programming concepts to children, with prime focus to children with autism. The game consists of two parts: a playable introduction; and a coding interface. In the playable introduction the user accompanies VHs that lost their emotions and have to learn about emotions by other VHs. The coding part requires dragging and dropping code to create the emotions of a $\mathrm{VH}$ depending on unambiguous stimuli they are presented with. In terms of adaptability the game gives children a library of VHs to choose from, but the VHs and the VE cannot be customised.

The Rapid Easy Authoring Platform for serious games (REAPS) [29] is an authoring platform that empowers lecturers and academics to easily create games-based learning content in the domain of Work Safety and Health. Content authors can create games and make them accessible to students through the Web. The platform supports the creation of games around two main formats "Spot the X" where players have to distinguish items that do not match the normal items in the scene and "Branching-Story" which represents a scenario as a tree of possible outcomes reflecting the players' actions. Although both game formats could benefit from using VHs as part of the gameplay, the platform does not support them.

However, despite the increased number of systems featuring VHs in various learning domains, current systems offer limited options to instructors to adapt the system to suit various scenarios within a single domain and apply gamified elements that would aid the educational experience. This is due to high cost and the complexity both, creating customised game content and assigning verbal and non-verbal behaviours of VHs to match the requirements of a game's premise. Typically, the environments that are available offer a level-builder that allows some degree of content adaptation. In particular, users can load a predefined 3D object in the builder and modify its appearance through a menu of choices. The main advantage of this approach is that the user can apply various props (e.g., hair, clothes, etc.) on the 3D mesh without modifying its basic attributes (e.g., animations, morphs, etc.).

Creating fully instructor-driven scenarios requires tools that allow the creation of:

- custom-made 3D environments (including the appearance of the models and the content of the dialogue between the student and the VHs); and

- gamified features (competition, time constrains, levels of difficulty, milestones, feedback etc.) that fully reflect a given scenario.

Design and development appealing and engaging SG that incorporate those features requires highly specialized game development skills. Currently there are no SG platforms that allow real-time authoring of roleplay simulations for learning without requiring hard core technical skills.

\section{Westminster Serious Games Platform}

The Westminster Serious Games Platform (wmin-SGP) empowers instructors/teachers/trainers/domain experts to create roleplay game simulations suitable for a concept that satisfied specific learning objectives without the need for specialised technical or artistic skills. It achieves this by providing a set of authoring tools that allow:

- the customization of the VE within which the roleplay simulation takes place;

- $\quad$ the selection of the VHs the users will interact with and the creation of the question and answer (Q\&A) pairs to which they would respond;

- the specification of the games goals and objectives.

The dialogue game play model which is supported is a back and forth discourse between a human user and a virtual human character and the program has to gather information and then direct the conversation down different pathways based on information received from the user. The system tracks context through conversation. There is no need to repeat the domain questions; the user can jump across topics and coordinate multiple input modes.

The following sub-sections expand on the wmin-SGP the development tools; architecture; and the supported modes of interaction.

\section{1 wmin-SGP development tools}

The wmin-SGP platform has been developed using Unity 3D game platform [58] coupled with the ICT Virtual Human toolkit [22]. The latter is an open-source collection of modules, tools and libraries that facilitates the creation of embodied VHs. Its main render is Unity3D that makes contents created with the toolkit accessible through the WWW through Unity's Web player. However, the current version of the toolkit is not compatible with Unity's Web Player and thus it cannot be accessed on tablets and iPads. Its distributed architecture however, makes possible to run the resource-hungry components (e.g., speech recognition, natural language processing components, etc.) on a powerful server.

\section{2 wmin-SGP system architecture}

The wmin-SGP is a 3D interactive system that allows multimodal interaction with VHs (play mode) in a single player environment; and dynamic creation of gamified scenarios and dialogues with the use of an intuitive graphical user interface (GUI) (edit mode). A unique selling point of this platform is that it allows real-time authoring of VEs featuring VHs and the addition of game mechanics matching different game premises. 
Additionally, it allows real-time authoring of multimodal content for VHs matching the communication and dialogue needs of different game premises. The platform has been designed and developed to assist:

- instructors to dynamically create roleplay simulations in a multimodal 3D VEs populated by VHs, without requiring technical knowledge (programming or 3D modelling skills); and

- $\quad$ learners to engage in real-life roleplay simulations assuming the role of a professional interacting with the VHs to extract information related to the situation they have to resolve to practice their professional skills. Learners are also allowed to create simulations.

The wmin-SGP edit mode (see Figure 1) consists of the following five components:

1. Scene Editor (SE), which offers a matrix-style environment where instructors/learners can develop custom-made scenes with fully-functional VHs.

2. Natural Language Components (NLC), which processes input text in plain English and generates relevant responses.

3. The Non-verbal Behaviour Generator (NVBG), a rule-based component that analyses a VH response and proposes appropriate non-verbal behaviours (gestures, face expressions and gases) which is defined in its behavioural file. A behavioural file contains rules that map certain words or part of speech (e.g., nouns, pronouns, etc.) to animations. Each rule has an associated priority value that helps the component to decide which rule to give precedence.

4. The Speech Components (SC), a Text-to-Speech (TTS) component generates the virtual human's speech and the timing needed to synchronize the speech with the non-verbal behaviours. Each virtual human can have a unique voice based on the available TTS engines on the target platform.

5. The Dialogue Editor (DE), a tool designed to help instructors/learners create dialogues and select relevant non-verbal behaviours. Dialogues are entered into the system in the form of Question and Answer (Q\&A) pairs.

The following section describes the wmin-SGP edit mode.

\section{3 wmin-SGP edit mode process}

To build a roleplay simulation, instructors/learners must go through the following steps:

1. Create the $3 D$ scene and bring in VHs Instructors/learners can load an empty environmental template (a standard office and a large meeting room) and populate it with 3D models (like desks, chairs, decorative items etc.) and VHs (15 VH models are offered with a list of characteristics, like gender, origin, age and dress code) to create a scene that fully reflects the requirements of a given scenario. The GUI offers tools and guidance to assist the editing process (see Figure 1). Objects have a standard menu with various manipulation options (e.g., move up or down, rotate, etc.). During the edit mode a dummy character placed in the environment provides a visual indicator of the user's viewpoint of the scene. This character cannot be seen in play mode.

2. Create a text based introduction - A field is provided to enter the instructions the players will receive explaining the game aims and objectives and what learners target to achieve.

3. Create Conversational Milestones - Conversational milestones are key-points in the dialogue that can be displayed to aid/direct the learners to elicit the required information via their interaction/communication with the VHs. Additionally, milestones offer feedback to students in order to self-evaluate their progress towards their goal.

4. Toggle simulation timer - Content authors can increase the level of challenge each scenario poses by adding a countdown timer. Learners have to play against time to meet the requirements of the scenario. The game ends once the allocated time has expired.

5. Create and assign dialogues to characters using a modified version of the virtual human builder (VHBuilder) - Instructors/learners define the verbal and non-verbal responses of the VHs in the scene. Q\&A pairs are entered in plain English and are linked to VHs and behavioural rules (animations, facial expressions) can be modified or created. The tool can access a number of predefined libraries of face, body and location animation (e.g., walking, running, etc.). The current version of the platform has a relatively limited library of animations. However, the platform is scalable and additional animations could be added.

Once a simulation is completed it is being added in a database/a library of simulations that can be accessed from a drop down menu either to run it in play mode or to edit it further.

\section{4 wmin-SGP play mode}

After game simulations have been created wmin-SGP play mode allows users/learners to run the simulations and interact in the VE. The core activity is to talk to the VHs and achieve the game simulation objectives as those are described in a set of instructions at the start of the game. The learners talk to the VHs trying to elicit pre-set milestones, either by typing text using the keyboard or talking to a microphone. The milestones are accomplished 
by asking the right question or responding in the expected way.

The role of the instructors is to assess how quickly and effectively the learners achieved the game objectives and if they use professional terminology.

The system could be used by the students to create game simulations. In this case the instructor's role would be to access the completeness and complexity of the created game simulation and the use of professional terminology.

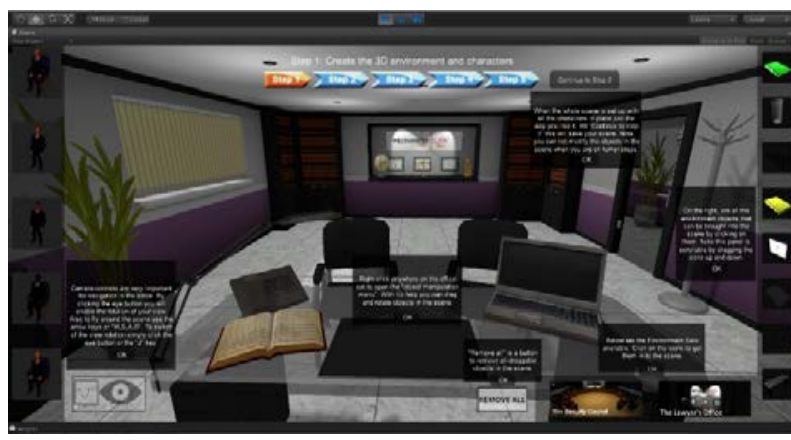

(a)

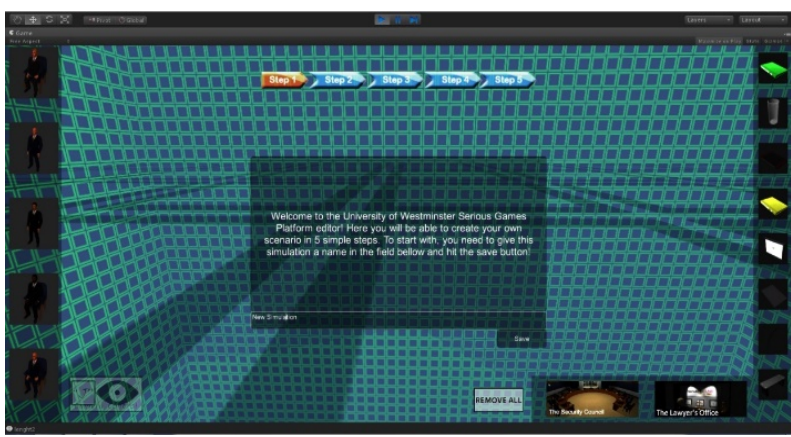

(c)

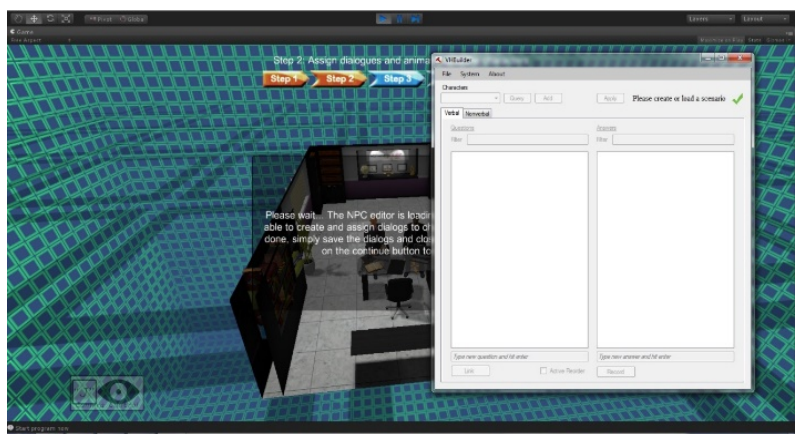

(e)

\section{Use Cases}

As stated previously (see section 1 and 2.1) roleplay simulations are presently successfully used at the Department of Politics and International Relations and the School of Law at the University of Westminster. To assist this practice we developed wmin-SGP (as presented in section 3) with the scope to provide academic staff (domain experts) without specialised skills in 3D animation and games with intuitive tools that would enable them to create bespoke game simulations, that suit their teaching requirements, and that could engage their

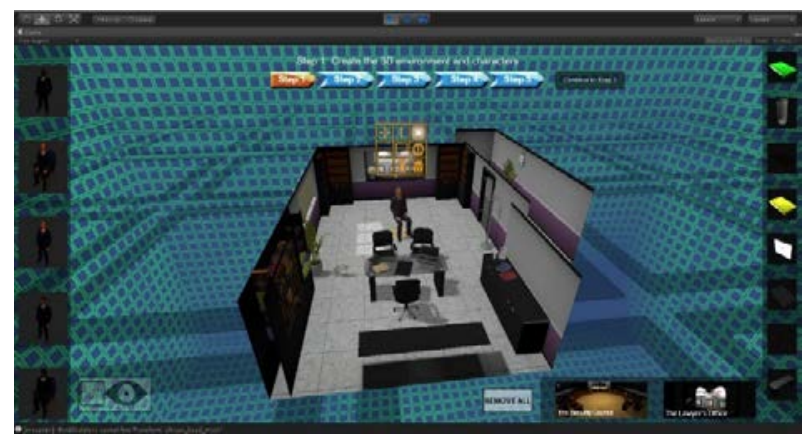

(b)

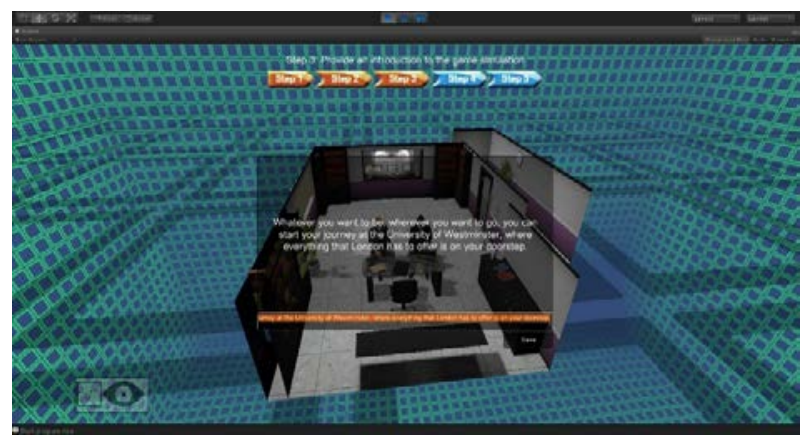

(d)

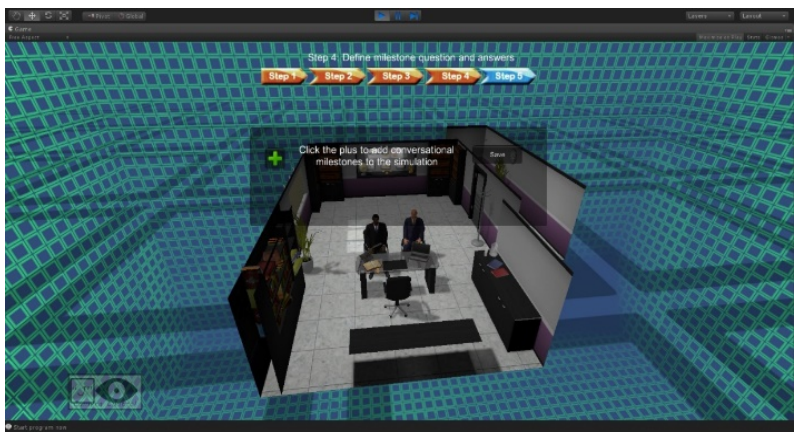

(f)

Figure 1. A screenshot of the edit mode of the wmin-SGP that provides guidance to the user to edit the scene and use the available editing tools. wmin-SGP edit mode consists of the following five stages: (a) (b) create the 3D scene and bring virtual humans in the scene; (c) Create a text based introduction that describes; (d) Create Conversational Milestones; (e) Toggle simulation timer; (f) Create and assign dialogues to characters using a modified version of the virtual human builder (VHBuilder). 
students more effectively with the learning activity. The wmin-SGP would also provide a tool for students to engage with playing interactive game simulations for as long as needed in order to equip themselves with the required skills to proficiently apply them in their domain.

To evaluate the pedagogic validity of wmin-SGP both as game simulation editing tool, as well as serious games play environment two use cases have been created. One use case is for politics and one for law. The use cases have been developed in close collaboration with domain experts that have been using successfully game simulations to support their teaching in International Politics and in Law. Those are described in the following sections (4.1 and 4.2).

\subsection{The Security Council use case}

One of the use cases that has been created was the "Security Council simulation" (see Figure 2) which is based on an actual meeting of the United Nations (UN) Security Council with topic "The situation in the Middle East” (United Nations S/PV.6930)[50]. Although the actual meeting resulted into "no-action", an expert in the domain of politics and international relations modified the contents of the meeting and added dialogue so that learners will have to achieve specific goals. The scenario consists of $15 \mathrm{UN}$ members. The learner plays the role of the coordinator of the UN meeting that gives turn to UN members, listens each member's positioning and based on the gathered information negotiates targeting at achieving a given goal.

\subsection{Robbery/burglary use case}

The law game simulation (see Figure 3) is based on the scenario of a robbery/burglary. In this incident a male middle age white character is a suspect of stealing $£ 50,000$ after an attack on the security guard and an elderly resident. The suspect was arrested and taken to the police station. He denies responsibility for the attack and taking the money. In the final simulation (play mode) the learners would have to ask the right questions in order to establish if the act was a robbery and burglary based on the law of those offences in the Theft Act 1968 and to produce a piece of practical and tactical advice for the police on evidence and law. This will test the skills of fact analysis, legal research, case strategy, application of law, and ultimately the production of legal advice, including questions that the police should ask. The learner takes the role lawyer asking the right questions to elicit the required information to correctly apply the law.

To study the effectiveness of wmin-SGP in terms of usability, as well as in terms of supporting the creation of motivating and engaging educational simulations we based our study on HCI heuristics and on the Octalysis gamification framework. Those are described in the section 5 and 6 below respectively.

\section{User evaluation}

The wmin-SGP has been evaluated with a small, but adequate number of expert users against Nielsen's list of usability principles [37][38] following a cognitive walkthrough method [30][43][62]. The process focused on assessing the platform's play mode and editing tools in creating bespoke game simulations that fulfil specific educational requirements. Six expert users (all computer literate and confident in the use of VEs and games) took the role of the instructor who uses the platform to create a game simulation and later the role of the student that plays the game simulation. According to Nielsen Normal Group the best results come from testing no more than 5 users and running as many small tests as you can afford [39][35].

The study was based on building the "Security Council" (see section 4.1) and the "Robbery/Burglary" (see section 4.2) use cases. Three expert users created the Security Council simulation and played the law simulation and vice versa.

The expert users have been asked to walk through the edit and play modes of wmin-SGP following an explicit list of expected user actions (UA) and system responses (SR) in order to create and play game simulations that have been described earlier and to provide feedback to the following set of questions:

(a) does the action match the user's goal at that point?

(b) will the user see the action is available?

(c) will the user recognise the action is the one they need?

(d) will the user understand the feedback they receive?

The expert users recorded their review for each task they had to perform to create a roleplay simulation electronically. The expert users have not received any training in using wmin-SGP, as this would affect the heuristic evaluation process. This process was tedious and it lasted almost 6 hours for each expert evaluator. The analysis resulted to an extensive list of usability, educational and gamified issues which are presented in the following sections.

\subsection{Security Council simulation}

Below we describe the wmin-SGP expert evaluation process of creating and playing the Security Council use case.

\subsubsection{Creation of a Security Council simulation}


To meet the requirements of the Security Council simulation (see section 4.1) the expert evaluators were asked to use the wmin-SGP edit tools to re-create the UN simulation (environment, VHs, dialogues). In principle this simulation involved 15 UN members with specific positioning over the topic "The situation in the Middle East" in order to achieve the best possible resolution to the benefit of the state they represented. The expert users would have to recreate the Security Council environment, the characters that took place (UN members) and the dialogues between them. UN members' positioning would have to be entered by the evaluators as dialogue assigned to the relevant VHs. Below, we present results related to the effectiveness and efficiency of the five editing steps of the wmin-SGP in creating a Security Council simulation:

1. Create the $3 D$ environment and the characters - The UN Security Council meeting requires a large meeting room with 15 desks and 15 participants. The participants are of various gender, age groups, origins and the have formal dressing code. The wmin-SGP platform offers a default large meeting room with desks, chairs and decorative items (microphones, labels and flags for the UN members)

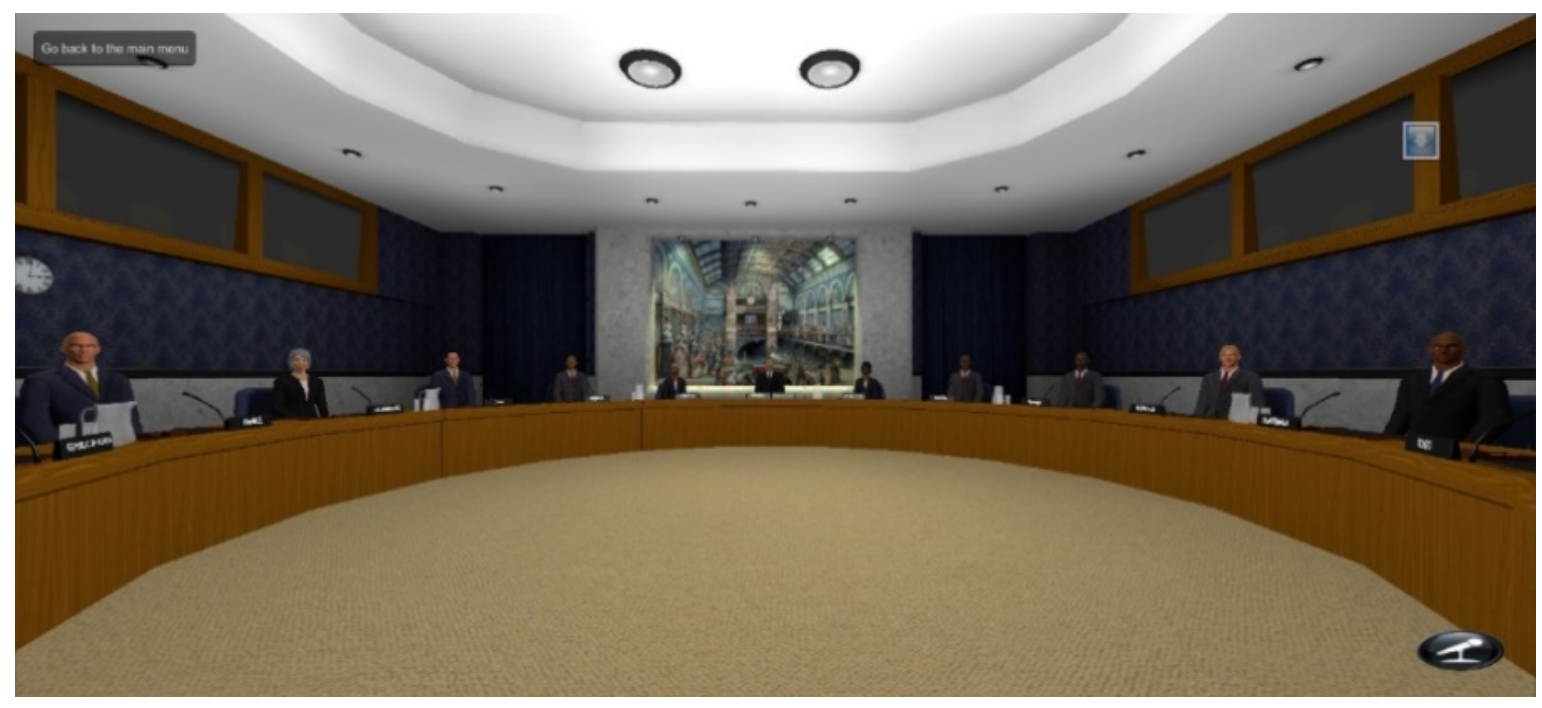

Figure 2. The Security Council scenario implemented in the wmin-SGP.

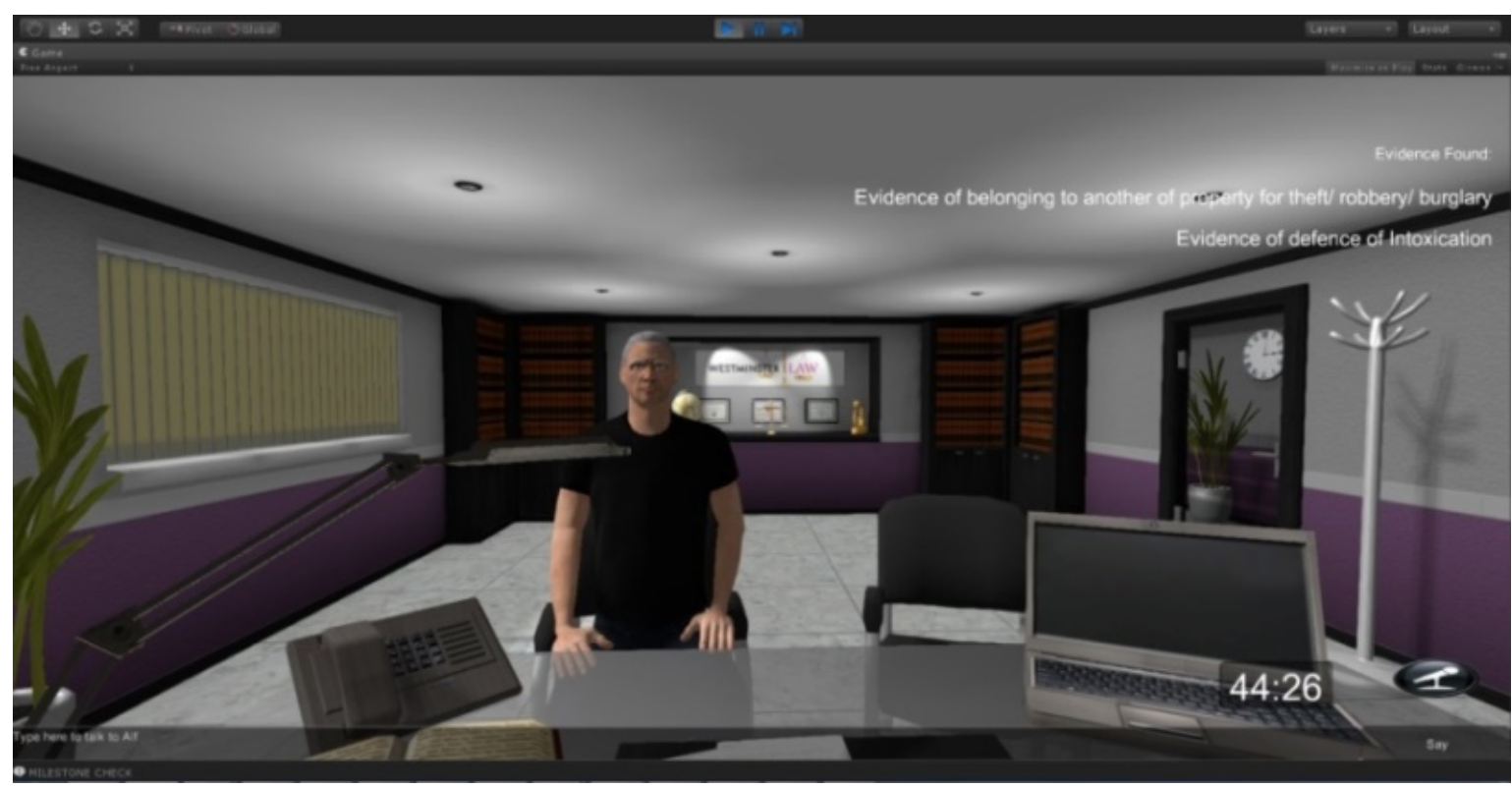

Figure 3. The Law scenario implemented in the wmin-SGP. 
that could be used to simulate a Security Council meeting. It also offers a library of 15 character models with a list of characteristics (see section 3) that completely satisfied the UN meeting simulation requirements. Objects and characters were brought in the scene just by dragging and dropping them from the respective libraries. The expert evaluation revealed the following issues related to GUI features that can be easily addressed in future version(s):

(a) one such problem is when users select multiple objects and those appeared as one lying on top of another, which makes it difficult to select and modify them;

(b) a button to restore the scene to the last saved state is missing;

(c) the activation of objects properties manipulation is not obvious to the user;

(d) navigation in the scene to view the environment is not straight forward and users need time to familiarise themselves navigating in the environment;

(e) the navigation tool that guide the users to different editing steps implies that the user can jump between editing steps, which is a feature that the system does not support.

2. Create an introduction what the game is about This step was forthright. The users added a description in a text field and moved to the next step.

3. Create conversational milestones for the application - Creating and editing milestones was straightforward. However, an important issue with this component is its position in the editing process which would be more logical to appear after having assigned dialogues to a $\mathrm{VH}$.

4. Toggle simulation timer - Interestingly, the instructors stated that the timer could be used more effectively if the Conversational milestones were related to time (e.g., achieve 2 milestones in 2 minutes). Such a feature could be used to trigger additional aid (e.g. educational resources) that the learners could consult in case they could not achieved a milestone in a specific timeframe. In addition, learner performance indicators or "gamified" features could be linked with time and milestones. For example, a power bar could be included to show the students' performance, or to attract the user's attention.

5. Create and assign dialogues to characters using the VHBuilder - This step allows instructors/learners to use an external to Unity tool called Dialogue Editor $^{\S \S}$ to define the verbal (set of Q\&A pairs) and non-verbal responses (animation of the body and the facial expressions) of the VHs in the scene. An

\footnotetext{
$\S \S$ The Dialogue Editor tool is a modified version of VHBuilder a tool provided by the ICT Virtual Human Toolkit for the rapid prototyping of virtual human multimodal content (verbal and non-verbal behaviours)
}

important issue regarding this tool was related to the guidance through the editing process. The users have to create a new simulation scenario, then they have to query the scene to get the list of the present VHs to whom they can then assign Q\&A pairs and nonverbal responses. This process is mystifying. The GUI and user assistance for the completion of this step needs to be reviewed. In addition, a problem that was clearly revealed with the specific scenario was remembering the $15 \mathrm{VHs}$ names and the effect of the animation linked to each Q\&A pair which is extremely hard with this amount of characters. Another problem is the legibility of the visual clues of the linked Q\&A pairs, which is messy. In addition, once a Q\&A pair is linked to a $\mathrm{VH}$ it cannot be unlinked.

\subsubsection{Playing the Security Council simulation}

As stated in section (4.2) the Security Council simulation learners adopt the role of the UN meeting coordinator that gives turn to the presenters (UN member), listens carefully each presenter and gathered information and negotiation techniques used by the UN members to achieve the best possible resolution to the benefit of the state they represented.

The expert evaluators were asked to take the role of the student, go through the process and state any issues with the clarity of the procedure. The expert evaluators followed the same process of answering the set of four questions for every expected UA and SR (as stated above) and suggested the review of various features of wminSGP play mode to improve its playability and educational validity. Those are listed below:

1. The incorporation of a visual indication of:

(a) the length of the simulation and the duration that each speaker is expected to speak;

(b) the sequence the speakers are expected to speak;

(c) turn taking, a clue that a speaker completed his/her positioning, or how much of their positioning have they covered (this is rather helpful when a speaker has to talk for a long period of time).

2. Increase the interaction between the user and the characters, for example, the role of the user as a coordinator should be increased in the UN scenario.

3. Include gamified and educational features like scoring/evaluating the use of diplomatic language against some criteria set by the instructor (e.g., formality of the language, plurality of arguments, evidence or historical references) by each council member after they have completed their positioning. Each criterion should have a specific scale/rating. The system could provide a visual indicator of the average score given by the user for each topic, as well as the total score for the whole session. At the end of the interaction the individual and total score could be compared with what the lecturer has initially specified. The scoring could trigger 
feedback on whether or not the use of diplomatic terminology by each security-council member was correct.

4. Each scenario in politics has either a resolved or an unresolved outcome. In both cases the system should give the student the choice to select the outcome (either resolved our unresolved or no outcome) and justify his/her decision. This could be done by the system providing a list of topics based on which decision should be taken and allowing to rate each topic that needs to be satisfied. For example, a topic could be considered as correct provided that the user gives a rating within a specific range, and the system would give accordingly feedback.

\subsection{Law, Robbery/Burglary simulation}

Below we describe the wmin-SGP expert evaluation process of creating and playing the Law use case.

\subsubsection{Creating the Law simulation}

The Law simulation (see Figure 3) is based on the scenario of a robbery/burglary as stated in section (4.2). The learner takes the role of the lawyer asking the right questions to elicit the required information to correctly apply the law. In principle this simulation involves two characters, a lawyer and a client. Those characters meet at a lawyer's office and a rich dialogue between them is supported in order to allow the learner/lawyer to extract the right level of information and detail to best support his/her client.

The expert evaluators that took the role of the instructor had to create an environment that simulated a lawyer's office with two characters, the client/suspect and the lawyer. A set of Q\&A pairs had to be assigned to the character embodying the suspect. The user/learner takes the role of the lawyer asking the right questions to elicit the required information to correctly apply the law.

Base on the expert evaluators' report no new issues arose regarding the use of the first four editing steps of wmin-SGP (see section 3.3) to create the law simulation compared to the ones already identified for the creation of the Security Council simulation (as in section 5.1.2). The law scenario required the creation of an office environment with one middle age participant. The platform offers an office environment with various decorative items that could be useful in an attorney's office and a large library of VHs, so the selection of an appropriate character was straight forward. The only new issue that arose was related to step five the creation of the Q\&A pairs and their categorisation to different dialogue states that would provide the required evidence for the resolution of the case. The instructor would like to be able to categorise series of Q\&A pairs in the DE to the following states:

- $\quad$ personal status;

- $\quad$ work status;

- $\quad$ impact of redundancy;
- details of the action, possible robbery/burglary.

Such categorization could aid support related to the progress within the game.

\subsubsection{Playing the Law simulation}

As stated above the learners at this simulation plays the role of a lawyer interacting with the suspect to elicit the required information to correctly apply the law. After experiencing the law simulation as student the expert evaluators suggested the incorporation of a list of tools and updates that could be used to improve the educational value of the simulation:

1. The inclusion of a permanent visual aid to remind the user the purpose/goals of the scenario. This would assist the user interaction with the system, such as initiating the dialogue and asking the right questions.

2. The database of Q\&A pairs should be large to satisfactorily imitate natural language recognition. Visual indications for the dialogue states (and substates) are required to guide the user to progress from one dialogue stage to another, for example when the layers extracts information about the clients personal status.

3. Currently when VHs do not understand questions posted to them they reply with a "false response" (like a series of messages around the phrase of "I do not understand this question”). False responses do not engage the user to formulate the question. As a result of sequential false responses the system should be able to analyse the context of the question and give a related answer (not random) so the dialogue could progress to the next state.

4. The lecturer should be able to specify a degree of confidence of each scenario (i.e., on a scale from 1 10) about the possibility to successfully defend the case by applying the law based on the client's provided evidence. The learner would have to figure out based on the dialogue and visual clues provided by the VH or the system, whether the case is strong enough or not. Depending on the confidence level of each scenario the $\mathrm{VH}$ could become uneasy or relaxed as more milestones were found.

5. Upon completion of the simulation the system should indicate appropriate law that could be used to defend the client or provide access to material that could help the user to take a decision of how to best defend the client (like the resolution of previous cases). In the case that the user would not select the right law, the system could provide guidance for relative reading or other educational resources.

The heuristic evaluation process identified various issues related to:

- the effectiveness of wmin-SGP - which is about providing the required tools to complete given tasks;

- $\quad$ the visibility of the system status - keeping the user informed about what is going on through appropriate 
system response and feedback within reasonable time;

- $\quad$ the terminology used in the system and how phrases and concepts are familiar to the users and support them in completing their tasks;

- $\quad$ user control of the tasks to be completed - providing tools to recover from mistakes or errors;

- recognition rather than recall - meaning minimize the user's memory load by making objects, actions, and options visible.

During this process the expert evaluators provided suggestions and recommendations of how the gamification of the platform could be improved. However, the usability principles fell short to evaluate if wmin-SGP supported the creation of motivating and engaging educational simulations. For this purpose a second expert evaluation was conducted following the Octalysis gamification framework, which is covered in the following section.

\section{Framework evaluation based on Octalysis gamification framework}

\subsection{Octalysis gamification framework}

Octalysis is a framework that organizes systematically a list of gamified elements or cognitive drives (see Figure 4) that can be used in UCD to make an application engaging and motivating [1]. The framework suggests that almost every game is "fun" because it appeals to certain core drives within humans that motivate players towards certain activities. The Octalysis framework organizes those motivating factors into the following 8 core drives which is based on an octagon shape, hence its name:

1. epic meaning is the need to participate in something bigger than just yourself;

2. development and accomplishment is about motivating people because they are feeling that they are improving, they are levelling up and achieving mastery;

3. empowerment of creativity and feedback is the core drive that motivates people to incorporate their creativity, try different combinations and strategies, seek feedback and adjust;

4. ownership and possession is the primary core drive that motivates people to accumulate possessions, improve it, protect it and get more;
5. social influence and relatedness refers to the activities motivated by the influence of other people (e.g., by what other people do or think);

6. scarcity and impatience is what motivates people to want something they cannot have (e.g., because it is not immediately or easily obtainable);

7. unpredictability and curiosity is willingness to discover the unknown outcome and involve chance;

8. loss and avoidance refers to the motivating factors that help people avoid situations they do not want happening (e.g., to die in a game).

Within Octalysis, the core drives on the right (see Figure 4) are considered Right Brain core drive and are related to creativity, self-expression and social aspects. The Left Brain core drives have a tendency of being more based on Extrinsic Motivation which means that the motivation is to obtain something, whether it is a goal, a good, or anything you cannot obtain. The core drives on the left (see Figure 4) are considered Left Brain core drives and are associated to logic, calculations and ownership. The Right Brain core drives have a tendency of being based on Intrinsic Motivations [47] which means that the motivation is that the activity itself is rewarding on its own and you do not need a goal or a reward.

Some extra dimension to the framework is that the top core drives in the octagon are considered very positive motivations - white hat, while the bottom core drives are considered more negative motivations - black hat. The white hat gamification involves motives that engage the user/player in activities that allow expressing creativity, and achievement through skill mastery, which encourages a higher sense of meaning, confidence and empowerment. The black hat gamification on the other hand involves motives that drive active engagement based on uncertainty and the fear of losing something. Such type of interaction nurtures bad emotions. To achieve good gamification all 8 core drives should be considered on a positive and productive activity so that everyone ends up happier and healthier [5].

Section (6.2), below reviews the gamified features that are supported by wmin-SGP using the Octalysis framework. This analysis provides an indication of how satisfactory the platform supports tools that allow the creation of engaging and motivating educational experiences; and how balanced those motivational elements are, based on the Octalyis framework.

\section{2 wmin-SGP evaluation based on the Octalysis framework Core Drives}


Creating an experience incorporating the right game mechanics and game design techniques to engage and motivate people to achieve their learning objectives requires deep analysis, reasoning, testing and adjusting. This section reports expert evaluation results of wminSGP against Octalysis core drives (see section 6.1) based on six expert users using the Octalysis Tool [40]. This is an online tool that allows evaluators to assess a product/process against the Octalysis core drives using a scale of one to ten, where 10 is "best", and based on the overall scoring it reports on how well those have been incorporated in the system/process. The scope of this evaluation was to review both the wmin-SGP play mode features and the editing tools (see sections 3.3 \& 3.4) that are used to create bespoke game simulations.

The expert users were given a thorough demonstration politics and for law (see section 4). They have been asked to provide a score for each of the Octalysis core drives for wmin-SGP tools and a short justification for their score. Below we provide a summary of the evaluators reasoning of their review, while figure 5 presents the average rating provided by the expert users for each core drive accompanied by a graph created automatically by the Octalysis Tool that demonstrates the balance between the core drives. The Octalysis Tool provides also a summary of the overall balance between the core drives in order to create motivating and engaging simulations.

Epic meaning and calling - wmin-SGP is designed for the creation of simulations that support learners to practice their professional role for which they are being trained. For example the user takes the role of a lawyer, a counsellor who intends to defend a person in need, or help

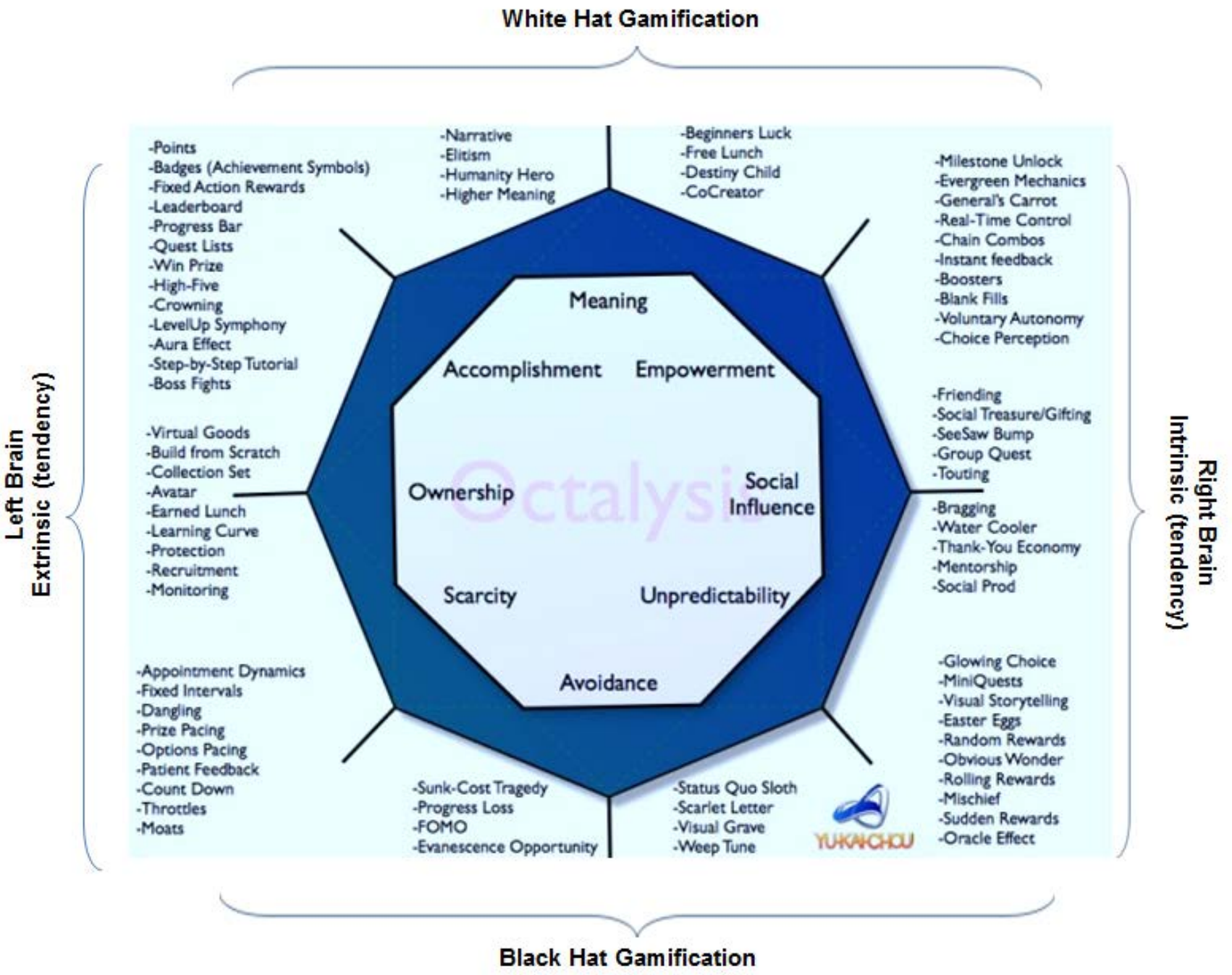

Figure 4. The Octalysis Gamification Framework [2]

of the edit and play modes of wmin-SGP and they spend enough time getting familiar with it. Then they followed an explicit list of expected user actions to create the two game simulations that have been outlined earlier for their client respectively, or a political leader who is involved in influencing public policy and decision making. The simulations engage the learners in a narrative that involves elicitation of information to apply the law, 
extract evidence based on which to defend a client, provide the best advice to their client, negotiate or take political decisions. Thus, the platform is considered as a tool that strongly supports meaning.

Development and accomplishment - wmin-SGP provides an environment that supports a step-by-step process that helps the learners achieve a set of milestones linked to learning goals. Milestones could be associated with points or badges to be won that could reveal their level of achievement.

Empowerment of creativity and feedback - is supported in terms of unlocking milestones and controlling the narrative and the way that the activity advances in realtime. There are various directions that empowerment narratives. The five steps process of building simulations presented in (section 3) assists monitoring the process of creating the simulations. The system allows the creation of a library/collection of simulations that could be linked when the learners progress through their learning journey.

Social influence and relatedness and scarcity and impatience are not supported by the platform. Social influence and voting are interesting concepts with potentially strong benefit to learning to be exploited.

Unpredictability and curiosity - is supported as far as visual storytelling is concerned, gradually discovering clues and collecting information that aids the creation of the broader images of a simulation based on which decision making can occur.

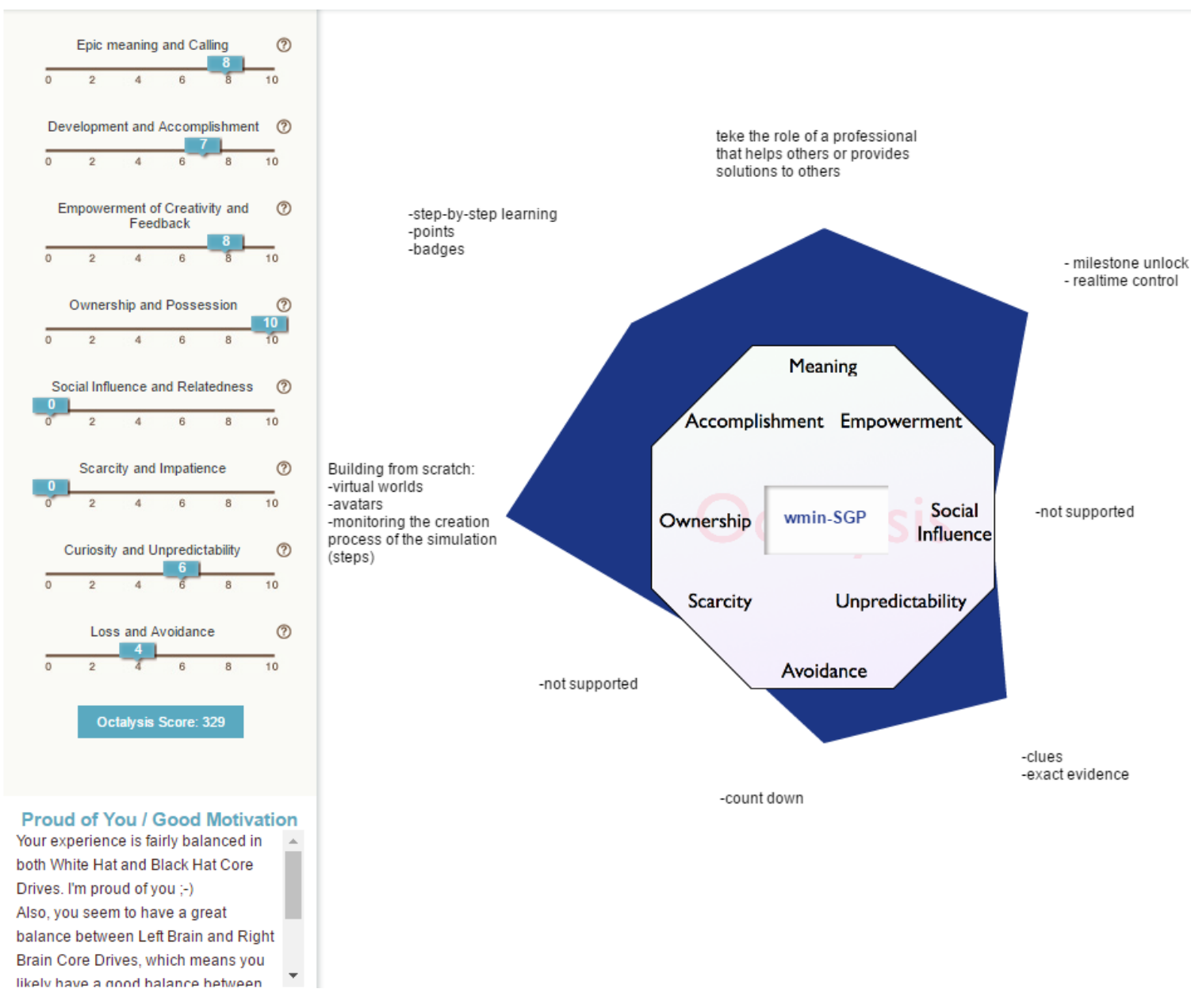

Figure 5. Average of the score provided by expert users to wmin-SGP using the Octalysis Tool.

could be enhanced that would be very suitable to the abovementioned learning activities. By providing instant feedback and awarding learners with boosters for example.

Ownership and possession - is strongly supported by the wmin-SGP, as the whole concept of the platform is based on allowing building from scratch bespoke simulations, with custom made virtual worlds, avatars and
Loss and avoidance - is supported in terms of increasing the level of challenge each scenario poses by adding a countdown timer. The learners have to play against time to meet the requirements of the scenario. The game ends once the allocated time has expired. An interesting concept that could increase or sustain engagement would be to add a factor of negative marking, loosing points or boosters that have been gained, that 
could be linked to time that a task is completed or the learner to progress to the next level.

The accumulative score for wmin-SGP based on the experts review the Octalysis Tool provided was 329 (see Figure 5) out of 800 maximum that could have been achieved if all core drives achieved a score of 10 . However, a good incorporation of game elements does not necessarily need to achieve the maximum score on all core drives. Good gamification is related to considering all 8 core drives on a positive and productive activity [5]. Based on this score the Octalysis Tool provided a review that reflects the balance between the Octalysis core drives (see Section 6.1 and Figure 5): "this score demonstrates that the platform allows the creation of fairly balanced simulations in both White Hat and Black Hat core drives. In addition, it showed that there is a good balance between Left Brain and Right Brain core drives, which means that there is a prospective to support a good equilibrium between Intrinsic and Extrinsic Motivation”.

\section{Conclusions and future directions}

In this paper we presented a platform that allows: realtime authoring of roleplay simulations allowing the dynamic creation of 3D scenes; and verbal and non-verbal interaction with fully embodied VHs to simulate a number of hypothetical scenarios to support educational purposes without requiring technical knowledge. We conducted two types of expert evaluation to study the effectiveness of the platform in terms of usability, as well as in terms of supporting the creation of motivating and engaging educational simulations based on HCI heuristics and using the Octalysis gamification framework. The expert evaluation revealed that regardless various usability issues, the wmin-SGP allows the dynamic creation of multiple scenarios for professional training. The expert evaluation of wmin-SGP gamified features using the Octalysis gamified framework disclosed an encouraging review of supporting fairly balanced simulations that can lead to the creation of motivating and engaging experiences. Those results derived by evaluating wminSGP for the creation of two educational use cases in higher education, for the political and legal sectors.

The study indicated four main directions for future development of the wmin-SGP:

- $\quad$ interface design, the interface needs to be refined to improve both the edit and the play mode process. Regarding the edit mode, priority needs to be given in incorporating the identification of milestones and setting time duration respectively within the dialogue editor. Visual aids need to be provided to assist the user with viewing the effect of the animation linked to non-verbal interaction to be able to assign the appropriate verbal and non-verbal utterances to the right character. Regarding the play mode, the GUI needs to be refined to effectively guide the user to complete each stage of the game and to progress to the next one.
- $\quad$ gamification, improving or adding various game-like features to better assist educational purposes. For example linking milestones with time duration/constraints for the completion of a task, offering a scoring system linked to the resolution of the simulation and linking this to the provision of educational support (like feedback and direction to relative readings/resources).

- $\quad$ improving the VHs' contextual awareness to be able to intervene when necessary to engage the users in social interaction. Emphasis should also be on improving the VHs' contextual awareness and the integration of more advanced sensing and $\mathrm{VH}$ technologies (e.g., MultiSense, FLoReS and Cerebella) to enable to intervene if needed and enable affective learning. Extending the platform to support social influence, should be exploited.

- deploy wmin-SGP on the cloud, currently wmin-SGP requires a high spec computer to run, as the ICT tool that enables rich interaction with VHs involves resource intensive processing power. In order to make wmin-SGP platform accessible over the web and on multiple platforms and devices it is important to consider the decomposition of wmin-SGP GUI to the backend tools that enable rich interaction with VHs and deploying the advances processing procedures using the parallel computing technology.

In addition, the Octalysis framework core drives need to be evaluated to assess how effectively learning is addressed as at the moment the framework does not evaluate learning as such.

\section{Acknowledgements.}

Fragmented content of this paper has been presented previously in the $14^{\text {th }}$ International Conference on Interactive Mobile Communication Technologies and Learning (IMCL 2014), November 13-14, 2014, Thessaloniki, Greece and as part of a Special Session in Cognitive Serious Gaming (CSG) within the $1^{\text {st }}$ Immersive Learning Research Network Conference (iLRN), July 13-14, 2015, Prague, Czech Republic.

\section{References}

[1] Abodor, H. \& Daneshfar, A. (2006) Management simulations: determining their effectiveness, Journal of Management Development, 25(2): 151-168.

[2] Argyriou, L. Klavdianos, P. Wall, J. Rivera, M.F. Hajimirza, N. Apostolakis, K. Daras, P. Kordelas, G. Tsiodras, T. Zahariadis, T. KuiJK, F. STEVens, C. Broeck, V.S. Quacchio, E. Poulakos, S. \& Marra, A. (2013) WP3 D3.2 Report on design specification of graphical user interface for use case 1, FP7-ICT-287723-REVERIE, URL: http://www.reveriefp7.eu/resources/deliverables/ [Accessed 31 March 2016].

[3] Becker, B. \& MARK, G. (1998) Social Conversation in Collaborative Virtual Environments. In Proceedings of the Collaborative Virtual Environments (CVE'98), D. SNOWDON \& E. ChURChILl [eds.], University of Manchester, June 17-19 (Springer Verlag), 47-56. 
[4] BuRKe, B. (2014) Gamify: How gamification motivates people to do extraordinary things, Bibliomotion Inc.

[5] Chou, Y. (20015) Actionable Gamification: Beyond Points, Badges, and Leaderboards (Octalysis Media).

[6] Deterding, S., Dixon, D., Khaled, R. \& Nacke, L. (2011) From game design elements to gamefulness: defining "gamification". In Proceedings of the 15th International Academic MindTrek Conference: Envisioning Future Media Environments (MindTrek '11), NY, USA (New York: ACM), 9-15.

[7] Doswell, J. \& Harmeyer, K. (2007) Extending the 'Serious Game' Boundary: Virtual Instructors in Mobile Mixed Reality Learning Games. In Proceedings of Digital Games Research Association International Conference (DiGRA 2007), Tokio, Japan, 524-529.

[8] Doumanis, I., Economou, D. \& Georgalas, N. (2015) The REVERIE Human Representation Addresses Issues Related to Virtual Presence, Communication, and Interaction in Collaborative Virtual Environments. In proceedings of the Computer and Information Technology; Ubiquitous Computing and Communications; Dependable, Autonomic and Secure Computing; Pervasive Intelligence and Computing (CIT/IUCC/DASC/PICOM), 2015 IEEE International Conference on, Liverpool, 2015 (IEEE) 1584-1589.

[9] Economou, D., Doumanis, I., Bouki, V., Pedersen, F., Kathrani, P., Mentzelopoulos, M. \& Georgalas, N. (2014) A dynamic roleplay platform for simulations in legal and political education. In Proceedings of the 8th International Conference on Interactive Mobile Communication Technologies and Learning (IMCL-2014), Thessaloniki, Greece (IEEE), 232-236.

[10] EkMAN, P. \& Fiesen, W. (1978) Facial Action Coding System: A Technique for the Measurement of Facial Movement (Palo Alto: Consulting Psychologists Press).

[11] Filbert, A. (2003) The Art of the 'Impossible': Writing Peace Agreements During War (PSOnline), 765-768.

[12] Finkelstein, S.L. NiCKEL, A., HARrison, L., Suma, E.A \& BARNES, T. (2009) cMotion: A new game design to teach emotion recognition and programming logic to children using virtual humans. In Proceedings of IEEE Virtual Reality Conference (IEEE Press), 249-250.

[13] Flanagan, M. (2013) Critical Play: Radical Game Design, MIT Press.

[14] Fullan, M. \& Langworthy, M. (2014) A Rich Seam: How New Pedagogies Find Deep Learning, London, Pearson.

[15] Garris, R., Ahlers, R. \& Driskell, J.E. (2002) Games, motivation, and learning: A research and practice model. Simulations and Gaming, 33(4), 441-447.

[16] Goodwin, C. (1986) Gestures as a Resource for the Organisation of Mutual Orientation, Semiotica, 62(1/2): 29-49.

[17] Graesser, A.C., Chipman, P., Haynes, B.C. \& Olney, A. (2005) AutoTutor: An intelligent tutoring system with mixed-initiative dialogue. IEEE Transactions in Education, 48, 612-618.

[18] Craig, J. (ed.) (2011), The International Political Education Database (IPED), PSA Teaching and Learning Specialist Group.

[19] Green, K. \& Armstrong, J.S. (2011) Role thinking: Standing in other people's shoes to forecast decisions in conflicts. International Journal of Forecasting, 27(1), 6980.

[20] Hamari, J., Koivisto, J. \& Sarsa, H. (2014) Does Gamification Work?-- A Literature Review of Empirical
Studies on Gamification, (HICSS). In Proceedings of the 2014 47th Hawaii International Conference on System Sciences (HICSS '14), Washington, DC, USA, (IEEE Computer Society), 3025-3034.

[21] HuizingA, J. (1950) Homo ludens: a study of the playelement in culture, (Beacon Press).

[22] ICT Virtual Human Toolkit, Institute for Creative Technologies (ICT), University of Southern California, California, USA, $2014 . \quad$ URL: https://vhtoolkit.ict.usc.edu/documentation/ [Accessed 31 March 2016].

[23] Jones, K. (1995) Simulations: A handbook for teachers and trainers ( $3^{\text {rd }}$ ed.) (London, UK: Kogan Page).

[24] Kahneman D. (1973) Attention and Effort (NJ: Prentice Hall, Inc.).

[25] KAPP, K.M. (2012) The Gamification of Learning and Instruction: Game-Based Methods and Strategies for Training and Education (John Wiley \& Sons).

[26] KILLE, K. (2002) Simulating the Creation of a New International Human Rights Treaty: Active Learning in the International Studies Classroom. International Studies Perspectives, 3(4), 271-290.

[27] Koster, R. (2013) Theory of Fun for Game Design, 2 edition (O'Reilly Media).

[28] LENerT, M.E. (2012) Simulations and Games for Teaching Law: What's Possible? In Proceedings of Meaningful Play, East Lansing, MI, USA, October 18 - 20, 2012.

[29] LEONG P. \& GoH, V. (2013) REAPSG: Work safety and health games for construction sector, Games Innovation Conference (IGIC), 2013 IEEE International, Vancouver, BC (IEEE) 134-137.

[30] Lewis, C., Polson, P., Wharton, C., \& Rieman, J. (1990) Testing a walkthrough methodology for theory-based design of walk-up-and-use interfaces. In Proceedings of ACM CHI'90 Conf., Seattle, WA, April 1-5 (ACM), 235242.

[31] Magnenat-Thalmann, N. \& Kasap, Z. (2009) Virtual Humans in Serious Games. In Proceedings of CyberWorlds, 2009. CW '09, Bradford, 2009, 71-79.

[32] MARsh, B. (2012) Blended Learning: Creating Learning Opportunities for Language Learners, Cambridge University Press.

[33] MAYO, M.J. (2007) Games for science and engineering education, Communications of the ACM, 50(7): 31-35.

[34] McGonigal, J. (2012) Reality is Broken: Why Games Make Us Better and How They Can Change the World, (Vintage).

[35] NESTA Futurelab, “Close to $60 \%$ of UK Teacher's Want Computer Games in the Classroom" (2006), URL: http://www.nestafuturelab.org/about us/press releases/pr11.htm.

[36] NewmanN, W.W., \& Twigg, J.L. (2000) Active Engagement of the Intro IR Student: A Simulation Approach, Political Science \& Politics, 33(4): 835-842.

[37] Nielsen, J. (1995) 10 Usability Heuristics for User Interface Design, URL: https://www.nngroup.com/articles/ten-usability-heuristics/ [Accessed 31 March 2016].

[38] Nielsen, J. (1994) Heuristic evaluation. In Nielsen, J., \& MACK, R.L. [Eds.], Usability Inspection Methods, (John Wiley \& Sons, New York), ch. 2.

[39] Nielsen, Jakob, ANd Landauer, Thomas K. (1993) A mathematical model of the finding of usability problems. In Proceedings of ACM INTERCHI'93 Conference, 
Amsterdam, The Netherlands, 24-29 April 1993 (ACM), 206-213.

[40] Octalysis Tool URL: http://www.yukaichou.com/octalysis-tool// [Accessed 31 March 2016].

[41] Phillips, E. (2012) Law Games - Role Play And Simulation In Teaching Legal Case studies Application And Practical Skills: A Case Study. Compass: Journal of Learning and Teaching at the University of Greenwich, 5: $1-14$.

[42] PIVEC, P. (2009) Game-based Learning or Game-based Teaching? Becta Leading Next Generation Learning, URL:

http://dera.ioe.ac.uk/1509/1/becta_2009_emergingtechnolo gies_games_report.pdf [Accessed 1 April 2015].

[43] Polson, P., LeWis, C., Rieman, J. \& Wharton, C. (1992) Cognitive walkthroughs: A method for theory-based evaluation of user interfaces. International Journal of Man-Machine Studies, 36(5): 741-773.

[44] Poulakos, S. Klavdianos, P. Argyriou, L. Apostolakis, K. Alexiadis, D. Wall, J. DE Vet, J. Fechteler, P. \& BAKKeR, M. (2013) WP3 D3.3 Report on design specification of graphical user interface for use case 2, FP7-ICT-287723 - REVERIE, URL: http://www.reveriefp7.eu/resources/deliverables/ [Accessed 31 March 2016].

[45] Ramsden, P. (1988) Context and Strategy, Situational Influences on Learning. In R.R. SCHMEсK [ed.], Learning Strategies and Learning Styles (Springer Science + Business Media), ch. 7.

[46] RiCKEL, J. (2001) Intelligent Virtual Agents for Education and Training: Opportunities and Challenges, A. DE Antonio, R. Aylett, \& D. BALlin [eds.], Intelligent Virtual Agents (Berlin Heidelberg: Springer-Verlag), ch. 2.

[47] RYAN, R.M. \& DECI, E.L. (2000) Self-determination theory and the facilitation of intrinsic motivation, social development, and well-being, American psychologist, 55(1): 68-78.

[48] SABIN, P. (2014) Simulating War: Studying Conflict through Simulation Games (Bloomsbury Academic), Reprint edition.

[49] SACKS, H. (1992) Lectures on Conversation, Cambridge, (MA: Blackwell).

[50] S/PV.6930 http://www.un.org/en/ga/search/view_doc.asp?symbol=S/ PV.6930 [Accessed 31 March 2016].

[51] SHAFFER, D.W. \& GEE, J.P. (2008) How Computer Games Help Children Learn (Macmillan).

[52] Silverman, G. (2012) Law games: The importance of virtual worlds and serious video games for the future of legal education. In E. RuBin. [ed.], Legal Education in the Digital Age (Cambridge University Press), ch. 6.

[53] Simpson, A. \& KAussler, B. (2009) IR Teaching Reloaded: Using Films and Simulations in the Teaching of International Relations. International Studies Perspectives, 10(4): 413-427.

[54] SMetanA, L.K. \& Bell, R.L. (2012) Computer Simulations to Support Science Instruction and Learning: A critical review of the literature, International Journal of Science Education, 34(9).

[55] SMITH, R. (2010) The Long History of Gaming in Military Training, Journal Simulation and Gaming archive, 41(1): 6-19.
[56] Stover, W.J. (2007) Simulating the Cuban Missile Crisis: Crossing Time and Space in Virtual Reality, International Studies Perspectives, 8(1): 111-120.

[57] Sykes, J., Oskoz, A. \& Thorne, A.S. (2008) Web 2.0, synthetic immersive environments, and mobile resources for language education. CALICO Journal, 25(3): 528-546.

[58] SUNRISE URL: http://www.sunrisevr.com/stem-and-uscompetitiveness/\#.Vv-qj6QrKhd

[59] Tiwaria, S.R., Nafeesa, L. \& Krishnanb, O. (2014) Simulation as a pedagogical tool: Measurement of impact on perceived effective learning, The International Journal of Management Education, 12(3): 260-270.

[60] UNITY3D URL: http://unity3d.com/ [Accessed 31 March 2016].

[61] UsHeRwood, S. (2009) Enhancing student immersion in negotiation-based learning environments. International Journal of Learning, 16(7): 607-614.

[62] Wharton, C., Rieman, J., Lewis, C. \& Polson, P. (1994) The cognitive walkthrough method: A practitioner's guide. In NiELSEN, J. \& MACK, R.L. (eds.), Usability Inspection Methods, (New York: John Wiley \& Sons), ch.5.

[63] Wilson, L. (2009) Best practices for using games \& simulations in the classroom, Guidelines for $K-12$ Educators, Software and Information Industry Association (SIIA), Education Division.

[64] Wrzesien M. \& AlCAÑIZ Raya, M. (2010) Learning in serious virtual worlds: Evaluation of learning effectiveness and appeal to students in the E-Junior project. Computers \& Education, 55(1): 178-187. 